\title{
Oxycodone ameliorates the inflammatory response induced by lipopolysaccharide in primary microglia
}

This article was published in the following Dove Press journal: Journal of Pain Research

\author{
Jishi Ye' \\ Hong Yan ${ }^{2}$ \\ Zhongyuan Xia' \\ 'Department of Anesthesiology, \\ Renmin Hospital of Wuhan University, \\ Wuhan, 430060, Hubei, People's \\ Republic of China; ${ }^{2}$ Department of \\ Anesthesiology, The Central Hospital \\ of Wuhan, Tongji Medical College, \\ Huazhong University of Science and \\ Technology, Wuhan, 430000, People's \\ Republic of China
}

\begin{abstract}
Background: Activation of microglia participates in a wide range of pathophysiological processes in the central nervous system. Some studies reported that oxycodone (6-deoxy7,8-dehydro-14-hydroxy-3-O-methyl-6oxomorphine) could inhibit the overactivation of glial cells in rats' spinal cords. In the present study, we observed the effect of oxycodone on inflammatory molecules and pathway in lipopolysaccharide (LPS)-stimulated primary microglia in rats. Materials and methods: Neonatal rats' primary microglia were exposed to various concentrations $(25,50,100 \mathrm{ng} / \mathrm{mL})$ of oxycodone for $1 \mathrm{~h}$ after LPS stimulation for $24 \mathrm{~h}$. The levels of pro-inflammatory mediators, IL- $1 \beta$, TNF- $\alpha$, and TGF- $\beta 1 /$ smad $2 / 3$ signaling pathway were measured. The activation situation of microglia and the expression of T $\beta \mathrm{R} 1$ were observed by immunofluorescence.

Results: Oxycodone at $25 \mathrm{ng} / \mathrm{mL}$ did not change the levels of proinflammatory molecules and TGF- $\beta 1 /$ smad $2 / 3$ signaling pathway in primary microglia, which was increased by LPS. Oxycodone at 50 and $100 \mathrm{ng} / \mathrm{mL}$ could significantly suppress LPS-induced production of TNF- $\alpha$ and IL- $1 \beta$ and the expression of TNF- $\alpha$ mRNA, IL- $1 \beta \mathrm{mRNA}$, and TGF- $\beta 1 / \mathrm{smad} 2 / 3$ signaling pathway. Conclusion: These findings indicate that oxycodone, at relatively high clinically relevant concentration, can inhibit inflammatory response in LPS-induced primary microglia. The detailed mechanism needs to be investigated in future.
\end{abstract}

Keywords: oxycodone, inflammatory, microglia

\section{Introduction}

Microglia, innate immune cells of the central nervous system (CNS), are considered to be important participants in the natural immunity and adaptive immunity of the CNS. ${ }^{1}$

Activation of microglia by injury or external stimulus is widely perceived as contributing to a series of inflammatory signaling pathways and produces various proinflammatory cytokines, involved in a broad range of pathophysiological conditions, including neurodegeneration, neuropathic pain, and traumatic brain injury. ${ }^{2,3}$ Therefore, suppression of these inflammatory molecules, such as IL- $1 \beta$ and TNF- $\alpha$, may be a potential and effective therapeutic method to mitigate the progression of previously mentioned neuroinflammatory conditions.

Oxycodone (6-deoxy-7,8-dehydro-14-hydroxy-3-O-methyl-6oxomorphine), $\mu$ and $\kappa$ opioid receptor agonist, is widely used for the treatment of a large variety of painful disorders. ${ }^{4}$ Previous studies have shown that controlled-release oxycodone improved pain management after uterine artery embolization for symptomatic fibroids, and relieved neuropathic pain in diabetic patients. ${ }^{5,6}$ And in an animal model, oxycodone was
Department of Anesthesiology, Renmin Hospital of Wuhan University, 99 Zhang Road, Wuhan 430060, Hubei, People's

Republic of China

Tel +86 I 3808628560

Fax +86 278804 19l I

Email xiazhongyuan2005@aliyun.com 
reported to suppress the overactivation of glial cells and the subsequent release of pro-inflammatory cytokines. Besides, dextromethorphan could potentiate the effects of oxycodone. ${ }^{7}$ However, little is known about the effect of oxycodone on the inflammatory response in microglia in vitro.

Some studies and experimental models have confirmed that lipopolysaccharide (LPS) can induce inflammatory response and promote the release of proinflammatory cytokines in microglia. ${ }^{8,9}$ So, in this study, we attempt to investigate whether oxycodone could reduce the production of proinflammatory molecules and regulate the signaling pathway associated with inflammatory response. This study may provide several novel directions in understanding the analgesic and anti-inflammatory effect of oxycodone in patients and animal models.

\section{Materials and methods}

\section{Cell culture}

Male neonatal Sprague-Dawley (SD) rats were purchased from the center for disease control and prevention in Hubei Province. All related animal protocols were carried out according to the US National Institutes of Health Guide for the Care and Use of Laboratory Animals and approved by the Experimental Animal Center Review Board of Wuhan University (Wuhan, People's Republic of China).

Microglial cultures were prepared as previously described. ${ }^{8,9}$ In brief, using 75\% alcohol to disinfect skin, healthy 1-day old SD rats were decapitated and the brain tissue removed on an ultraclean bench. Then the brain tissue was placed in a sterile petri dish containing precooled PBS (Genom, Hangzhou, People's Republic of China) solution, cleaned twice. The meninges and cerebellum were removed from the excised brain, and the peeled cerebral cortex was cut up fully with a mesh bag $(300 \mu \mathrm{m})$ and trypsinized. After centrifugation $(120 \times g$ for $10 \mathrm{~min})$, supernatant was discarded and the cells were resuspended in DMEM/Nutrient Mixture F-12 (DMEM/F12) (Thermo Fisher Scientific, Waltham, MA, USA). Then the cells were seeded in a T75 culture bottle and incubated at $37^{\circ} \mathrm{C}$ with $5 \% \mathrm{CO}_{2}$. The medium was replaced after $24 \mathrm{~h}$, and it was changed every 3 days after shaking the flasks to remove cellular debris and non-adherent cells. After 7-9 days' incubation, the supernatant that contained microglia were collected and centrifuged (120× $g$ for $5 \mathrm{~min}$ ). After removing the supernatant, cells were resuspended in DMEM/F12 and seeded onto poly-L-lysine coated 96-well tissue culture plates at $4 \times 10^{5}$ cells $/ \mathrm{cm}^{2}$. After $1 \mathrm{~h}$ incubation, the medium was changed, the remaining cells were cultured in DMEM/F12 containing 10\% fetal bovine serum, and used as microglial cultures for cell identification and the following experiments.

\section{Experimental protocol}

Microglial cells were randomly divided into the following five groups: 1) control group (the microglia in the untreated group with no LPS [from Escherichia coli; Sigma-Aldrich Co., St. Louis, MO, USA] and oxycodone [Mundipharma, Beijing, People's Republic of China]); 2) LPS group (the microglia were treated with $1 \mu \mathrm{g} / \mathrm{mL}$ LPS); and 3) $\mathrm{O}_{25}, \mathrm{O}_{50}$, and $\mathrm{O}_{100}$ (the cells were treated with $25,50,100 \mathrm{ng} / \mathrm{mL}$ oxycodone, respectively, for $1 \mathrm{~h}$ after the treatment with $1 \mu \mathrm{g} / \mathrm{mL}$ for $24 \mathrm{~h}$ ).

\section{Cell viability assay}

After the microglia were treated with different reagents, we used Cell Counting Kit-8 (CCK-8) assay to assess the effect of LPS and/or oxycodone on cells' viability according to the manufacturer's instructions (Beyotime, Shanghai, People's Republic of China). Microglia were plated into 96-well plates at a density of $1 \times 10^{5}$ cells per well and incubated at $37^{\circ} \mathrm{C}$ with $5 \% \mathrm{CO}_{2}$ for $24 \mathrm{~h}$ and then washed. Microglia were treated with different concentrations of oxycodone and/or LPS, then CCK-8 reagent $(10 \mu \mathrm{L})$ was added to each well. Four hours later, the absorbance for all wells was measured at $450 \mathrm{~nm}$ using a microplate reader (model: DR-200Bs, Diatek, Wuxi, China).

\section{RT-PCR}

According to the manufacturer's instructions, the total RNA was isolated from the primary microglia with Trizol Reagent (Thermo Fisher Scientific). Total RNA from these samples was reverse-transcribed into cDNA using PrimeScript $^{\mathrm{TM}}$ RT Reagent Kit with gDNA Eraser (TaKaRa, Kyoto, Japan). After reverse-transcription, the RT-PCR was performed using SYBR Green PCR Master Mix (TaKaRa). PCR primers were as follows (forward and reverse): TGF- $\beta 1$ : 5'-GTGGCTGAACCAAGGAGACG-3' and 5'-AGGTGTTGAGCCCTTTCCAG-3'; TNF- $\alpha$ : 5'-CACCACGCTCTTCTGTCTACTG-3', and 5' - GCTACGGGCTTGTCACTCG-3'; IL-1 $\beta$ : 5'-GTGGCAGCTACCTATGT CTTGC-3' and 5'-CCACTTGTTGGCTTATGTTCTGT-3'; GAPDH: 5'-CGCTAACATCAAATGGGGTG-3' and 5'-TTGCTGACAATCTTGAGGGAG-3'. PCR amplification conditions: 40 cycles of denaturation at $95^{\circ} \mathrm{C}$ for $15 \mathrm{~s}$, annealing at $56^{\circ} \mathrm{C}$ for $20 \mathrm{~s}$, and extension at $72^{\circ} \mathrm{C}$ for $45 \mathrm{~s}$. The relative expression levels were calculated by the $2-\Delta \Delta \mathrm{Ct}$ method. The mRNA levels of the target gene were normalized to the levels of GAPDH. GAPDH was used as the endogenous "housekeeping" control gene for these analyses. 


\section{Cytokine assay}

The presence of TNF- $\alpha$, IL-1 $\beta$, and TGF- $\beta 1$ in the culture supernatant was determined using an ELISA kit (R\&D Systems, Inc., Minneapolis, MN, USA). The results were expressed in $\mathrm{pg} / \mathrm{mL}$.

\section{Western blot}

The protein extraction and Western blot were performed as described previously. Cultured cells were collected and cell lysates were prepared in the lysis buffer (Beyotime). The cell lysates were $\times g$ for $5 \mathrm{~min}$ at $4^{\circ} \mathrm{C}$ to collect the supernatants. Then the total protein concentrations in the supernatants were measured by BCA protein assay kit (Aspen, Wuhan, People's Republic of China). Protein samples $(30 \mu \mathrm{g})$ were subjected to electrophoresis on 10\% SDS-polyacrylamide gel (Aspen, Wuhan, China) and transferred to PVDF membranes (EMD Millipore, Billerica, MA, USA). After blocking with 5\% non-fat milk for $1 \mathrm{~h}$ at room temperature, the membranes were probed at $4{ }^{\circ} \mathrm{C}$ overnight with the following primary antibodies: 1:600 for $\mathrm{p}$-Smad2 (Cell Signaling, MA, USA), 1:600 for $\mathrm{p}-\mathrm{Smad} 3$ (Cell Signaling), and 1:5000 for GAPDH (Cell Signaling).

Secondary antibody (Kirkegaard \& Perry Laboratories, Gaithersburg, MD, USA) was used at a 1:10000 dilution for $30 \mathrm{~min}$ at room temperature. Finally, the immunoreactions were detected by enhanced chemiluminescence (Aspen) and visualized by Alpha Ease FC software for image analysis.

\section{Immunofluorescence}

The microglia from each group were seeded onto cover slips and fixed in $4 \%$ formaldehyde for $30 \mathrm{~min}$ at room temperature before cells permeabilized for $20 \mathrm{~min}$ in PBS containing $0.5 \%$ Triton X-100. The cells were incubated with a rabbit monoclonal antibody against CD11b (1:200, Abcam, Cambridge, UK) and T $\beta R 1$ (1:100, Abcam) respectively at $4{ }^{\circ} \mathrm{C}$ overnight. Next, after washing, cover slips were incubated for at least $1 \mathrm{~h}$ with TRITC-labeled goat anti-rabbit IgG or anti-mouse IgG (Aspen). Then cover slips were washed thee times with blocking buffer and cells were dyed nucleus with DAPI (Aspen) for $15 \mathrm{~min}$. Finally, the fluorescence signals were analyzed using a fluorescence microscope (Olympus Corporation, Tokyo, Japan).

\section{Statistical analysis}

The data were expressed as the mean \pm standard error of the mean. Statistical significance between groups was analyzed by using a one-way ANOVA with Tukey's multiple comparison test. A value of $P<0.05$ was accepted as statistically significant. All statistical analyses were performed using SPSS 11.0 software.

\section{Results \\ No significant change in the cell viability of microglia treated with oxycodone and/ or LPS}

As shown in Figure 1, cytotoxic effects of oxycodone and/ or LPS were tested by measuring the viability of microglial cells by using the CCK-8 assay. Compared with serum-free DMEM-treated group, the viability of microglia was not significantly changed by treatment with oxycodone and/or LPS ( $F=2.113, P=0.102)$.

\section{Oxycodone reduced the pro- inflammatory cytokines' production and downregulated the expression of related mRNAs}

Utilizing ELISA, we evaluated the effect of oxycodone on the release of LPS-induced cytokines, including TNF- $\alpha$ and IL-1 $\beta$, in culture supernatants. As shown in Figure 2A and $2 \mathrm{C}$, compared to control group, LPS could induce the inflammatory response in primary microglia and increase the production of TNF- $\alpha(P<0.01)$ and IL-1 $\beta(P<0.01)$. Treatment with oxycodone at $25 \mathrm{ng} / \mathrm{mL}$ had no effect on LPS-induced production of TNF- $\alpha$ and IL-1 $\beta(P=0.105)$. Treatment with oxycodone at 50 and $100 \mathrm{ng} / \mathrm{mL}$ could significantly suppress the levels of TNF- $\alpha$ and IL-1 $\beta$ in primary microglia (TNF- $\alpha$ : $P=0.034$ and IL-1 $\beta: P=0.0234$ ).

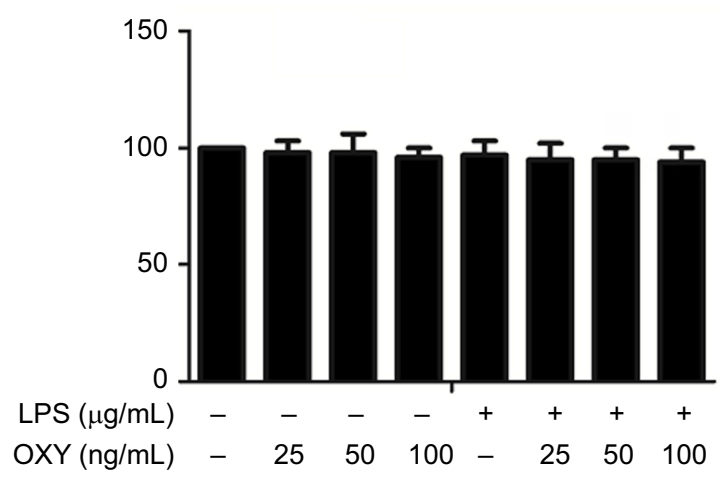

Figure I Cytotoxic effects of oxycodone and/or LPS on primary microglia. Notes: Microglial cell viability was tested by using CCK-8 assay. Microglial cells were treated with the indicated concentrations of oxycodone $(25,50$, and $100 \mathrm{ng} /$ $\mathrm{mL}$ ) for I $\mathrm{h}$ before LPS (I mg/mL) treatment for $24 \mathrm{~h}$. Bar charts indicate that oxycodone and/or LPS had no effect on cell viability. Data are mean \pm standard error of the mean and there was no change in the cell viability of microglia treated with oxycodone and/or LPS.

Abbreviations: LPS, lipopolysaccharide; CCK-8, Cell Counting Kit-8; OXY, oxycodone. 


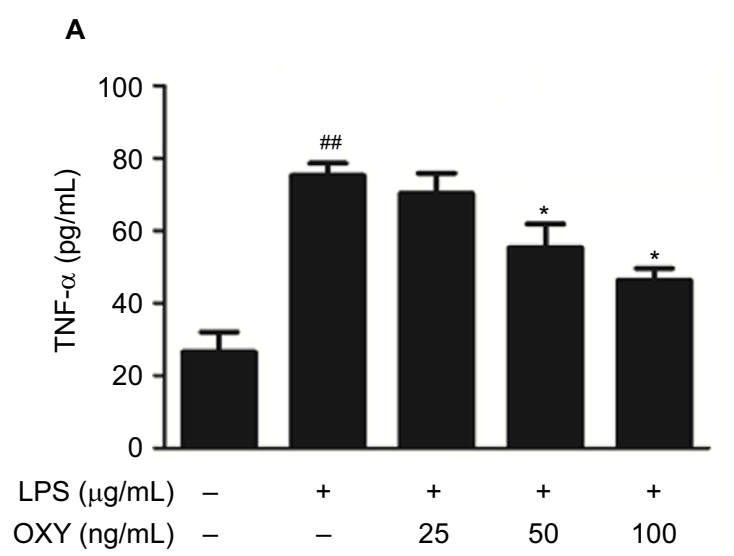

C

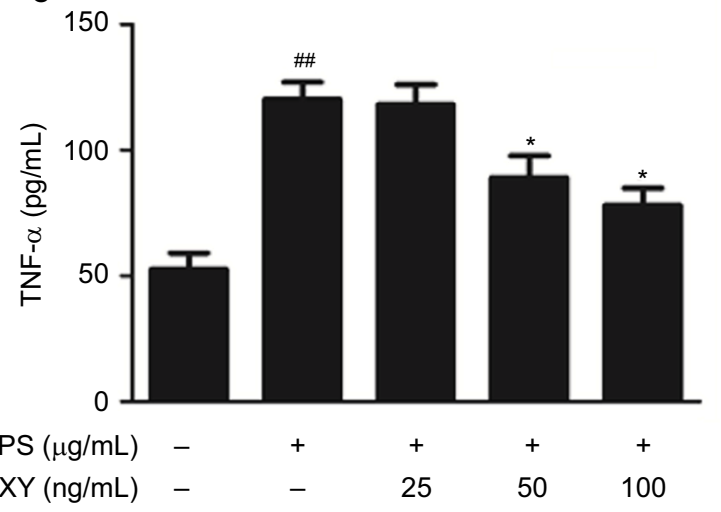

B

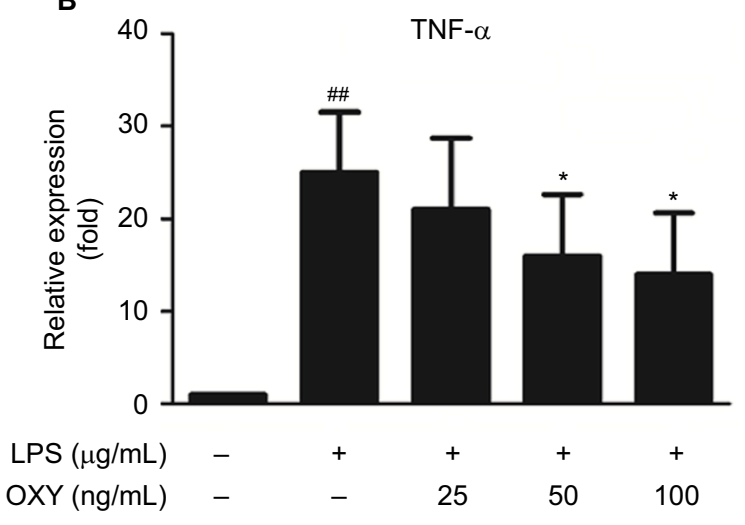

D

$\mathrm{IL}-1 \beta$

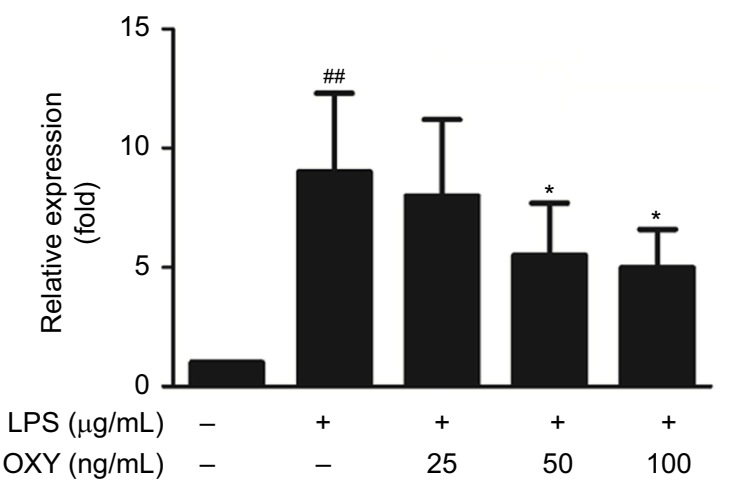

Figure 2 Effect of oxycodone on pro-inflammatory cytokine production and expression of related mRNA.

Notes: (A) ELISA was performed to detect the concentration of TNF- $\alpha$ in each culture medium. (B) qRT-PCR was performed to test the expression of TNF- $\alpha$ mRNA. GAPDH was used as the endogenous "housekeeping" control gene. (C) ELISA was performed to detect the concentration of IL-I $\beta$ in each culture medium. (D) qRT-PCR was performed to test the expression of TNF- $\alpha$ mRNA. GAPDH was used as the endogenous control gene. Data are mean \pm standard error of the mean. $n=3$, $P<0.0 \mathrm{I}$ vs control group; $* P<0.05$ vs LPS group.

Abbreviations: LPS, lipopolysaccharide; OXY, oxycodone.

To clarify the underlying mechanism responsible for the associated effect of oxycodone on cytokines in microglia, we subsequently detected the cytokines' mRNA expression using qRT-PCR. In line with the results acquired from cytokine production, LPS could increase the mRNA expression levels of TNF- $\alpha(P<0.01)$ and IL-1 $\beta(P<0.01)$ in primary microglia (Figure 2B and 2D).

Oxycodone at 50 and $100 \mathrm{ng} / \mathrm{mL}$ could significantly suppress the mRNA levels of TNF- $\alpha$ and IL- $1 \beta$ in primary microglia (TNF- $\alpha: P=0.040$ and IL-1 $\beta$ : $P=0.032$ ).

\section{Oxycodone downregulated the LPS-} stimulated inflammatory TGF- $\beta \mathrm{I} / \mathrm{smad} 2 / 3$ signaling pathway in primary microglia

Activated microglia leads to increased production of TGF$\beta 1$ cytokines which have anti-inflammatory actions. To investigate the effect of oxycodone on TGF- $\beta 1$ and $\operatorname{smad} 2 / 3$ expression in LPS-induced primary microglia, we examined the expression of TGF- $\beta 1$ mRNA, the concentration of TGF$\beta 1$, and the levels of its downstream mediators, including p-Smad2 and p-Smad3, by qRT-PCR, ELISA, and Western blot, respectively.

As shown in Figure 3, expression of TGF- $\beta 1$ mRNA and the concentration of TGF- $\beta 1$ were clearly increased in LPS-stimulated primary microglia, as well as its downstream mediators, $p-S m a d 2$ and $p-S m a d 3$ (TGF- $\beta 1$ mRNA: $P<0.01$; TGF- $\beta 1$ : $P<0.01$; $\mathrm{p}-\mathrm{Smad} 2$ and $\mathrm{p}-\mathrm{Smad} 3: P<0.01)$.

After treatment with oxycodone at 50 or $100 \mathrm{ng} / \mathrm{mL}$, oxycodone reduced the production of TGF- $\beta 1$ and downregulated the expression of TGF- $\beta 1 \mathrm{mRNA}$ in LPS-stimulated microglia (TGF- $\beta 1$ mRNA: $P=0.041$ and TGF- $\beta 1: P=0.037$ ). Likewise, Western blot showed that $\mathrm{p}-\mathrm{Smad} 2$ and $\mathrm{p}-\mathrm{Smad} 3$ were inhibited by oxycodone at 50 or $100 \mathrm{ng} / \mathrm{mL}$ in LPSinduced microglia (p-Smad2: $P<0.01$ and p-Smad3: $P<0.01$ ). 


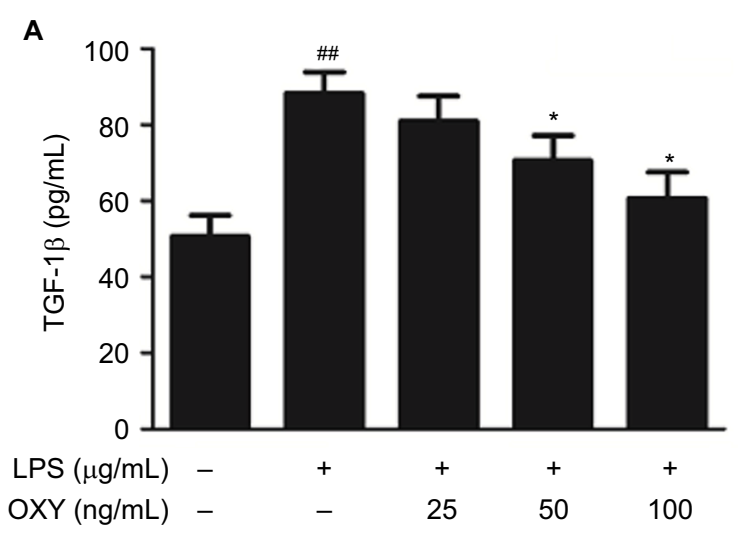

C

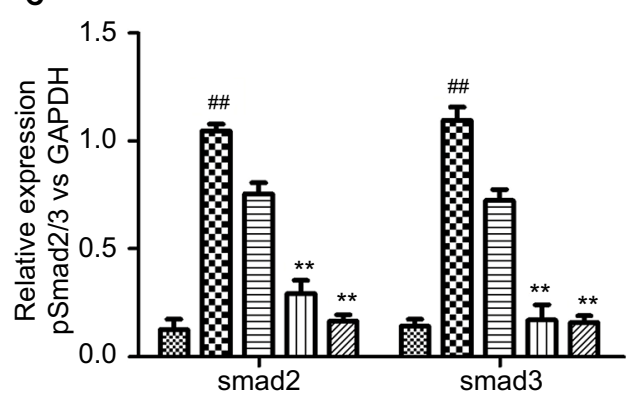

B

TGF-1 $\beta$

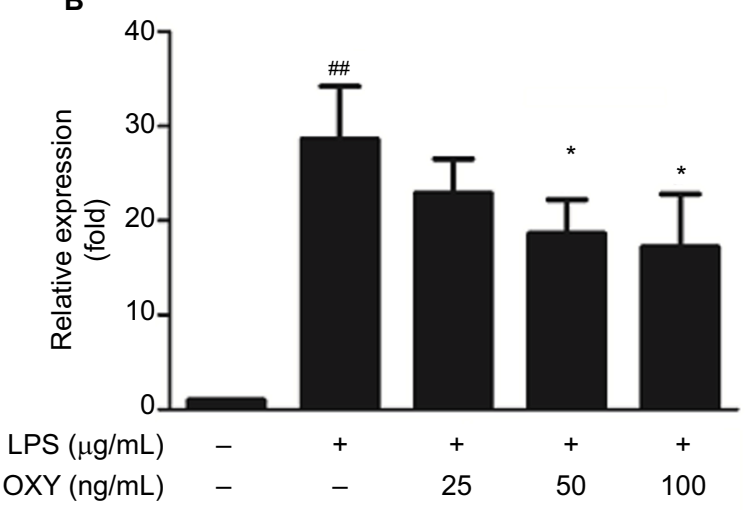

D

P-Smad3 $-\infty=52 \mathrm{kDa}$

P-Smad2 - - - - $=60 \mathrm{kDa}$

GAPDH

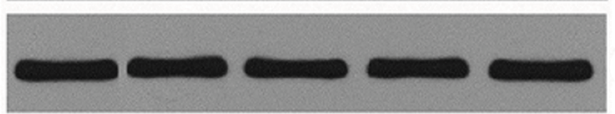

$37 \mathrm{kDa}$

Figure 3 Effects of oxycodone on TGF- $\beta 1 /$ smad2/3 signaling pathway in LPS-stimulated primary microglia.

Notes: (A) ELISA was performed to detect the concentration of TGF- $\beta$ I in each culture medium. (B) qRT-PCR was performed to test the expression of TGF- $\beta$ I mRNA. GAPDH was used as the endogenous control gene. (C and D) Western blot was performed to detect levels of pSmad2 and pSmad3. Bar chart demonstrates the ratio of pSmad2 and pSmad3 relative to GAPDH for each group. Data are mean \pm standard error of the mean. $n=3$, ${ }^{\# *} P<0.0$ I vs control group; ${ }^{* * P}<0.0$ I vs $L P S$ group; ${ }^{*} P<0.05$ vs LPS group.

Abbreviations: LPS, lipopolysaccharide; OXY, oxycodone; CON, control.

\section{Ib and T $\beta R$ I expression in cultured microglia}

To indicate the activation of microglia in each group, we tested the expression of microglial marker CD11b. A one-way ANOVA for the data reported in Figure 4 identified significant differences in CD11b expression (Figure 4; $F=99.816$, $P<0.01)$ among the groups. LPS could induce the activation of primary microglia and the expression of $\mathrm{CD} 11 \mathrm{~b}$ was clearly increased compared with control group $(P<0.01)$; compared with LPS group, oxycodone at 50 or $100 \mathrm{ng} / \mathrm{mL}$ suppressed the expression of $\mathrm{CD} 11 \mathrm{~b}(P=0.023$ and $P<0.01$, respectively).

To further investigate the expression of TGF- $\beta 1$ in primary microglia, we analyzed surface expression of T $\beta R 1$ on LPS-stimulated primary microglia. A one-way ANOVA for the data reported in Figure 5 identified significant differences in T $\beta R 1$ expression (Figure $5 ; F=41.242, P<0.01$ ) among the groups. LPS enhanced the surface expression of T $\beta \mathrm{R} 1$ on primary microglia $(P<0.01)$ and treatment with oxycodone at 50 or $100 \mathrm{ng} / \mathrm{mL}$ resulted in $\mathrm{T} \beta \mathrm{R} 1$ expression on the surface of primary microglia $(P=0.018$ and $P<0.01$, respectively). Collectively, oxycodone downregulated the LPS-stimulated inflammatory TGF- $\beta 1 / \mathrm{smad} 2 / 3$ signaling pathway in primary microglia (Figure 5).

\section{Discussion}

Our study's main findings are as follows: first, LPS at $1 \mu \mathrm{g} /$ $\mathrm{mL}$ can successfully induce activation of primary microglia and the activated microglia leads to a series of cytokine release. The TGF- $\beta 1 / \mathrm{smad} 2 / 3$ signaling pathway, which is a novel factor in cell cycle and associated with cell growth, apoptosis, and inflammatory response, is also upregulated in primary microglia induced by LPS. A low concentration of oxycodone $(25 \mathrm{ng} / \mathrm{mL})$ exerts no effect on the regulation of inflammatory molecules and pathways in activated primary microglia. Conversely, median and high concentrations of oxycodone (50 and $100 \mathrm{ng} / \mathrm{mL})$ are capable of inhibiting the pro-inflammatory cytokines, including IL- $1 \beta$, and TNF- $\alpha$ and the expression of mRNA. For TGF- $\beta 1 / \mathrm{smad} 2 / 3$ signaling pathway, median and high concentrations of oxycodone 

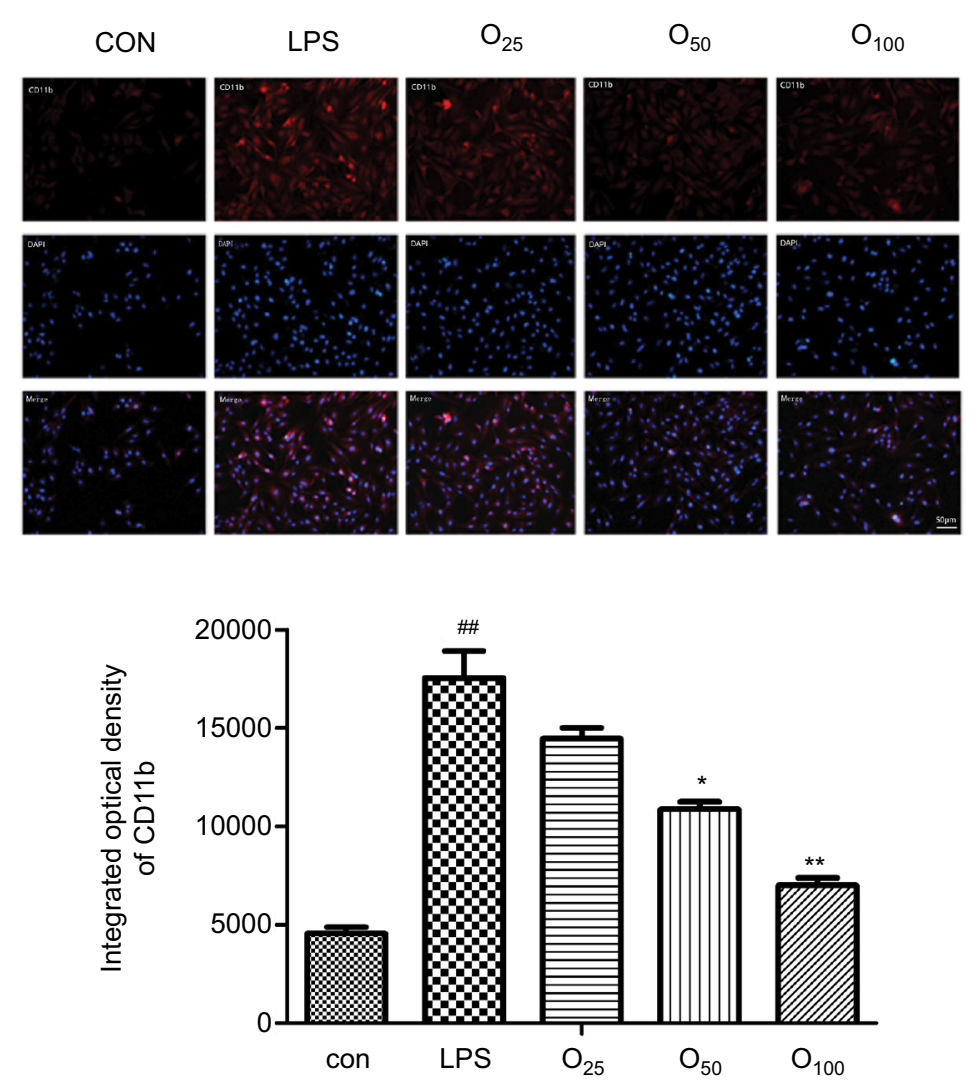

Figure 4 Effects of oxycodone on the expression of microglial marker CDI Ib in each culture medium.

Notes: Immunofluorescent staining was used to observe the expression of microglial marker CDII $\mathrm{b}$ in each group, which represented the activation situation of microglia. Oxycodone at 50 and $100 \mathrm{ng} / \mathrm{mL}$ alleviated LPS-induced upregulation of CDI lb in microglia. Original magnification $=\times 100$, scale bar: $50 \mu \mathrm{m}$. Data are mean \pm standard error of the mean. $n=3,{ }^{\#} P<0.01$ vs control group; $* * P<0.0$ I vs LPS group; $* P<0.05$ vs LPS group.

Abbreviation: LPS, lipopolysaccharide.

also exhibited the ability to inhibit TGF- $\beta 1$ protein, its downstream mediators $\mathrm{pSmad} 2 / 3$, and the surface expression of $\mathrm{T} \beta \mathrm{R} 1$ on activated primary microglia.

Based on a previous study, we found that LPS at $1 \mu \mathrm{g} / \mathrm{mL}$ can both activate primary microglia and have no effect on its cell viability. ${ }^{10}$ So, in vitro, we prepared primary microglia from neonatal rats' brain tissue to establish the inflammatory response model induced by LPS at $1 \mu \mathrm{g} / \mathrm{mL}$. The clinically relevant plasma concentration range of oxycodone is 5-50 $\mathrm{ng} / \mathrm{mL} .{ }^{11-13}$ Therefore, we consider $25-50 \mathrm{ng} / \mathrm{mL}$ as the range of clinically relevant concentrations achievable during oxycodone analgesia. Although oxycodone at $100 \mathrm{ng} / \mathrm{mL}$ is much higher than the clinical concentration, ${ }^{14}$ we could also observe its effects of cytotoxicity and inflammatory response on microglial cells and provide reference for opioid accumulation or abuse.

Exaggerated neuroinflammatory responses in the brain appear fundamental to neuroinflammatory-associated CNS disorders. Altered inflammatory potential in the brain is due, in part, to changes in microglia, the predominant innate immune cells of the brain and the major CNS source of inflammatory cytokines. ${ }^{15}$ Activated microglia play a pleiotropic and crucial role in the CNS pathophysiology process, for instance neurodegenerative disorder, traumatic brain injury, and neuropathic pain. ${ }^{16}$ In the early stage, activated microglia participate in maintaining tissue homeostasis, sensing the environment, searching for tissue damage or invading microorganisms, which play a positive and beneficial role in pathological processes. Nonetheless, when persistently activated, microglia ramp up a mass of pro- and antiinflammatory cytokines and apoptotic cascades, which lead to excessive and unnecessary neuron loss and CNS injury. ${ }^{17-19}$ In this regard, our data demonstrated that activated microglia could increase both pro-inflammatory molecules, IL-1 $\beta$, and TNF- $\alpha$, and anti-inflammatory cytokine, TGF- $\beta 1$. Both the increase of pro- and anti-inflammatory cytokines maintain a balance in the inflammatory response microenvironment. Meanwhile, our data also indicated that relatively high concentrations of oxycodone ( 50 and $100 \mathrm{ng} / \mathrm{mL}$ ) attenuated the pro-inflammatory cytokines, including IL-1 $\beta$ and TNF- $\alpha$, 

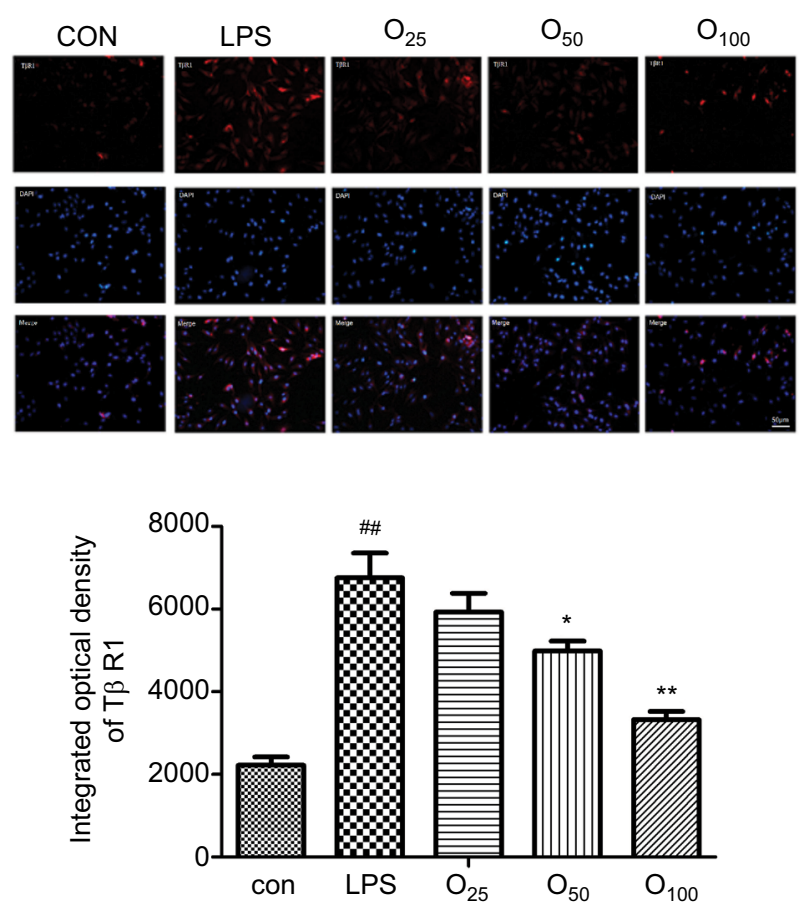

Figure 5 Effects of oxycodone on the expression of T $\beta R I$ in each culture medium. Notes: Immunofluorescent staining was used to observe the expression of T $\beta R I$ in each group, which represented the expression situation of TGF- $\beta$ I. Oxycodone at 50 and $100 \mathrm{ng} / \mathrm{mL}$ alleviated LPS induced upregulation of T $\beta R I$ in microglia. Original magnification $=\times 100$, scale bar: $50 \mu \mathrm{m}$. Data are mean \pm standard error of the mean. $\mathrm{n}=3,{ }^{\#} P<0.0$ I vs control group; ${ }^{* *} P<0.0$ I vs LPS group; ${ }^{*} P<0.05$ vs LPS group. Abbreviation: LPS, lipopolysaccharide.

and the expression of mRNA. Thus, oxycodone possesses a special advantage that other opioid drugs do not.

Oxycodone has been used in a clinical setting since 1917, and is increasingly used worldwide to treat acute and chronic pain in two types of dosage forms: oral administration and intravenous administration. ${ }^{20}$ Of note, although there are some limitations to the epidural administration of oxycodone, it could provide much higher cerebral spinal fluid concentrations, possibly better analgesic efficacy, and decrease the total dose of rescue fentanyl. ${ }^{21}$ Unlike other $\mu$-opioid analgesics, oxycodone provides not only potent analgesia but also has less side effects, such as low tolerance, respiratory depression, and pruritus. And recently, several studies indicated that oxycodone may have the property of relieving inflammatory response, in addition to its antinociceptive effects. In an in vivo model, Yang et al showed that oxycodone can ameliorate the spinal nerve injury-induced activation of glial cells (astrocytes and microglia) and plasma levels of proinflammatory cytokines (IL-6, IL-1 $\beta$, and TNF- $\alpha$ ) in rats, and co-administration of dextromethorphan potentiated this effect. ${ }^{7}$ Moreover, Yang et al also reported that oxycodone exerts protective effects on LPS-induced acute lung injury in rats and decreases the production of inflammatory cytokines, including IL-1 $\beta$, TNF- $\alpha$, and HMGB-1. ${ }^{22}$ Consistent with these results, our study found that oxycodone at 50 and $100 \mathrm{ng} / \mathrm{mL}$ attenuated upregulation of several inflammatory molecules in primary microglia induced by LPS. Furthermore, using immunofluorescence, we found that oxycodone can also decrease surface expression of T $\beta R 1$ on LPS-stimulated primary microglia, suggesting that oxycodone not only inhibits pro-inflammatory cytokines but also regulates anti-inflammatory cytokines in activated microglia. However, Kokki et al showed that oxycodone $(0.5-2 \mathrm{mM})$ has potential cytotoxicity in human neuroblastoma and mouse motoneuronal cells. ${ }^{23}$ These results seem to be in conflict with our present study. Some factors could explain this inconsistent phenomenon. First, our study utilized the microglial cells of neonatal rats rather that human neuroblastoma and mouse motoneuronal cells. Second, the time of oxycodone treatment was just $1 \mathrm{~h}$ rather than $24 \mathrm{~h}$ or 48 $\mathrm{h}$ as in Kokki's study. Due to the differences in exposure time and types of cultured cell lines, oxycodone may exhibit different degrees of cytotoxicity. For TGF- $\beta 1$, current evidence has focused on its multiple roles, including modulating inflammation and neuronal survival in neurodegenerative diseases and CNS injury. ${ }^{24-26}$ Chen et al demonstrated that TGF- $\beta 1$ could suppress glial and $\mathrm{T}$ cell-mediated neuroinflammation and thereby alleviate Alzheimer's disease-related neurodegeneration; ${ }^{27}$ furthermore, Huang et al reported that over-activated microglia surrounding neuritic plaques could recruit more neurotoxic microglia and lead to further neuroinflammation. ${ }^{28}$ They utilized TGF- $\beta 1$ to suppress the chemotactic migration of BV-2 microglia toward $A \beta$ aggregates, and its potential mechanism may be involved in SMAD signaling and downregulation of CCL5. In addition, TGF- $\beta 1 / \mathrm{smad} 2 / 3$ signaling has also been shown to be a "double edged sword" in several pain models. On the one hand, in chronic constriction injuryinduced neuropathic rats, Chen et al showed that suppressing p38 and ERK activity affects TGF- $\beta 1$-induced analgesia during neuropathy, suggesting that it may be a therapeutic target for neuropathic pain. ${ }^{29}$ However, in chronic pancreatitis, Zhu et al found that TGF $\beta 1$ enhanced neuronal excitability and increased the concentration of intracellular calcium. Furthermore, intrathecal injection of TGF $\beta 1$ produced abdominal hyperalgesia in healthy rats. ${ }^{30}$

Welser-Alves and Milner ${ }^{31}$ indicated that microglia, not astrocytes, are the major source of TNF- $\alpha$ and TGF $\beta 1$ in postnatal glial cultures, and that microglial production of these antagonistic cytokines is tightly regulated by cytokines such as LPS. Considering the viewpoint of this article, we suggested that oxycodone may ameliorate the whole activation 
degree of primary microglia induced by LPS and continue to keep a relative balance of pro- and anti-inflammatory molecules. And the expression of CD11b, which reflects activated state of microglia, can also support this explanation. Therefore, relatively high concentrations of oxycodone can both suppress the pro- and anti-inflammatory molecules and associated pathway. Certainly, more inflammatory cytokines need to be tested in future studies. Or rather, our results could be taken into consideration when choosing what analgesic is indicated during perioperative period and postoperative pain treatment. And these findings provide novel insight into the mechanisms by which oxycodone modulates microglia under inflammatory conditions.

Nevertheless, there are some limitations to our study. First and foremost, we did not explore the exact mechanism of regulation of oxycodone in LPS-induced primary microglia. Inflammatory response induced by LPS may be involved in TLK4/NF- $\mathrm{B}$ signaling pathway. ${ }^{31}$ We need to further investigate which molecule or mediator was blocked or inhibited by oxycodone in this pathway in LPS-induced primary microglia. In addition, for TGF- $\beta 1 / \mathrm{smad} 2 / 3$ signaling, it clearly had an anti-inflammatory effect on activated microglia. So, we need to further evaluate the dual inhibiting effect of oxycodone in activated primary microglia.

Second, several studies documented that plenty of stimuli could activate microglia, such as high glucose and hypoxia. ${ }^{32-35}$ These factors can also be linked to neuroinflammation or diabetic neuropathic pain models in microglia. Whether oxycodone has the dual inhibiting effect on activated microglia induced by different stimuli should be investigated in future studies.

\section{Conclusion}

In the present study, the findings indicated that oxycodone at 50 and $100 \mathrm{ng} / \mathrm{mL}$ suppresses the inflammatory response and inhibits TGF- $\beta 1 /$ smad $2 / 3$ signaling in LPS-induced primary microglia. Oxycodone might be an analgesic of choice when patients with neuroinflammatory diseases require pain relief.

\section{Acknowledgments}

This study was supported by the National Natural Science Foundation of China (grant no. 81671891). We thank the Central Laboratory (Renmin Hospital of Wuhan University) for the equipment and excellent technical assistance.

We also express our gratitude for some tips about experiments and paper writing from Dr. Lei Shaoqing and Dr. Meng Qingtao (Department of Anesthesiology, Renmin Hospital of Wuhan University).

\section{Author contributions}

All authors contributed toward data analysis, drafting and revising the paper and agree to be accountable for all aspects of the work.

\section{Disclosure}

The authors report no conflicts of interest in this work.

\section{References}

1. Spangenberg EE, Green KN. Inflammation in Alzheimer's disease: lessons learned from microglia-depletion models. Brain Behav Immun. 2017;61:1-11.

2. Sun L, Dong R, Xu X, Yang X, Peng M. Activation of cannabinoid receptor type 2 attenuates surgery-induced cognitive impairment in mice through anti-inflammatory activity. J Neuroinflammation. 2017;14(1):138.

3. Bi J, Shan W, Luo A, Zuo Z. Critical role of matrix metallopeptidase 9 in postoperative cognitive dysfunction and age-dependent cognitive decline. Oncotarget. 2017;8(31):51817-51829.

4. Schmidt-Hansen M, Bennett MI, Arnold S, Bromham N, Hilgart JS. Oxycodone for cancer-related pain. Cochrane Database Syst Rev. 2017;8:CD003870.

5. Freire GM, Cavalcante RN, Motta-Leal-Filho JM, et al. Controlled-release oxycodone improves pain management after uterine artery embolisation for symptomatic fibroids. Clin Radiol. 2017;72(5):428.e1-428.e5.

6. Gaskell H, Derry S, Stannard C, Moore RA. Oxycodone for neuropathic pain in adults. Cochrane Database Syst Rev. 2016;7:CD010692.

7. Yang PP, Yeh GC, Huang EY, et al. Effects of dextromethorphan and oxycodone on treatment of neuropathic pain in mice. J Biomed Sci. 2015;22:81.

8. Peng M, Ye JS, Wang YL, Chen C, Wang CY. Posttreatment with propofol attenuates lipopolysaccharide-induced up-regulation of inflammatory molecules in primary microglia. Inflamm Res. 2014;63(5):411-418.

9. Peng M, Wang YL, Wang CY, et al. Dexmedetomidine attenuates lipopolysaccharide-induced proinflammatory response in primary microglia. J Surg Res. 2013;179(1):e219-225.

10. Mayer AM, Murphy J, MacAdam D, et al. Classical and alternative activation of Cyanobacterium Oscillatoria sp. lipopolysaccharide-treated rat microglia in vitro. Toxicol Sci. 2016;149(2):484-495.

11. Samer CF, Daali Y, Wagner M, et al. The effects of CYP2D6 and CYP3A activities on the pharmacokinetics of immediate release oxycodone. $\mathrm{Br}$ J Pharmacol. 2010;160(4):907-918.

12. Kokki M, Heikkinen M, Välitalo P, et al. Maturation of oxycodone pharmacokinetics in neonates and infants: oxycodone and its metabolites in plasma and urine. Br J Clin Pharmacol. 2017;83(4):791-800.

13. Kokki M, Broms S, Eskelinen M, et al. Analgesic concentrations of oxycodone - a prospective clinical PK/PD study in patients with laparoscopic cholecystectomy. Basic Clin Pharmacol Toxicol. 2012;110(5):469-475.

14. Piirainen A, Kokki H, Immonen S, et al. A dose-finding study of dexketoprofen in patients undergoing laparoscopic cholecystectomy: a randomized clinical trial on effects on the analgesic concentration of oxycodone. Drugs R D. 2015;15(4):319-328.

15. Zheng B, Lai R, Li J, Zuo Z. Critical role of P2X7 receptors in the neuroinflammation and cognitive dysfunction after surgery. Brain Behav Immun. 2017;61:365-374.

16. Jassam YN, Izzy S, Whalen M, McGavern DB, El Khoury J. Neuroimmunology of traumatic brain injury: time for a paradigm shift. Neuron. 2017;95(6):1246-1265.

17. Ikawa D, Makinodan M, Iwata K, et al. Microglia-derived neuregulin expression in psychiatric disorders. Brain Behav Immun. 2017;61:375-385.

18. Salter MW, Stevens B. Microglia emerge as central players in brain disease. Nat Med. 2017;23(9):1018-1027. 
19. Kaur C, Rathnasamy G, Ling EA. Biology of microglia in the developing brain. J Neuropathol Exp Neurol. 2017;76(9):736-753.

20. Wiffen PJ, Wee B, Derry S, Bell RF, Moore RA. Opioids for cancer pain - an overview of Cochrane reviews. Cochrane Database Syst Rev. 2017;7:CD012592.

21. Kokki M, Välitalo P, Kuusisto M, et al. Central nervous system penetration of oxycodone after intravenous and epidural administration. $\mathrm{Br} J$ Anaesth. 2014;112(1):133-140.

22. Yang B, Zhang WD, Xia YM, et al. [Protective effects of oxycodone on lipopolysaccharide-induced acute lung injury in rats]. Zhonghua Yi Xиe Za Zhi. 2016;96(31):2498-2501. Chinese.

23. Kokki M, Pesonen M, Vehviläinen $\mathrm{P}$, et al. Cytotoxicity of oxycodone and morphine in human neuroblastoma and mouse motoneuronal cells: a comparative approach. Drugs R D. 2016;16(2):155-163.

24. Cunha SI, Magnusson PU, Dejana E, Lampugnani MG. Deregulated TGF- $\beta /$ BMP signaling in vascular malformations. Circ Res. 2017;121(8):981-999.

25. Shen WX, Chen JH, Lu JH, Peng YP, Qiu YH. TGF- $\beta 1$ protection against A $\beta 1-42$-induced neuroinflammation and neurodegeneration in rats. Int J Mol Sci. 2014;15(12):22092-22108.

26. Benkhoucha M, Molnarfi N, Dunand-Sauthier I, et al. Hepatocyte growth factor limits autoimmune neuroinflammation via glucocorticoid-induced leucine zipper expression in dendritic cells. J Immunol. 2014;193(6):2743-2752.

27. Chen JH, Ke KF, Lu JH, Qiu YH, Peng YP. Protection of TGF- $\beta 1$ against neuroinflammation and neurodegeneration in A $\beta 1$-42-induced Alzheimer's disease model rats. PLoS One. 2015;10(2):e0116549.
28. Huang WC, Yen FC, Shie FS, et al. TGF-betal blockade of microglial chemotaxis toward Abeta aggregates involves SMAD signaling and down-regulation of CCL5. J Neuroinflammation. 2010;7:28.

29. Chen NF, Chen WF, Sung CS, et al. Contributions of p38 and ERK to the antinociceptive effects of TGF- $\beta 1$ in chronic constriction injuryinduced neuropathic rats. $J$ Headache Pain. 2016;17(1):72.

30. Zhu Y, Colak T, Shenoy M, et al. Transforming growth factor beta induces sensory neuronal hyperexcitability, and contributes to pancreatic pain and hyperalgesia in rats with chronic pancreatitis. Mol Pain. 2012;8:65.

31. Welser-Alves JV, Milner R. Microglia are the major source of TNF- $\alpha$ and TGF- $\beta 1$ in postnatal glial cultures; regulation by cytokines, lipopolysaccharide, and vitronectin. Neurochem Int. 2013;63(1):47-53.

32. Su D, Cheng Y, Li S, et al. Sphk1 mediates neuroinflammation and neuronal injury via TRAF2/NF- $\mathrm{KB}$ pathways in activated microglia in cerebral ischemia reperfusion. J Neuroimmunol. 2017;305:35-41.

33. Wang X, Ma J, Fu Q, et al. Role of hypoxia-inducible factor- $1 \alpha$ in autophagic cell death in microglial cells induced by hypoxia. Mol Med Rep. 2017;15(4):2097-2105.

34. Sun Y, Xiao Q, Luo C, et al. High-glucose induces tau hyperphosphorylation through activation of TLR9-P38MAPK pathway. Exp Cell Res. 2017;359(2):312-318.

35. Bowyer JF, Tranter KM, Sarkar S, et al. Corticosterone and exogenous glucose alter blood glucose levels, neurotoxicity, and vascular toxicity produced by methamphetamine. $J$ Neurochem. 2017;143(2): $198-213$.

\section{Journal of Pain Research}

\section{Publish your work in this journal}

The Journal of Pain Research is an international, peer reviewed, open access, online journal that welcomes laboratory and clinical findings in the fields of pain research and the prevention and management of pain. Original research, reviews, symposium reports, hypothesis formation and commentaries are all considered for publication.

\section{Dovepress}

The manuscript management system is completely online and includes a very quick and fair peer-review system, which is all easy to use. Visit http://www.dovepress.com/testimonials.php to read real quotes from published authors. 